\title{
Modos de trabalhar e modos de subjetivar na agricultura familiar no sul do Brasil
}

\author{
Rita de Cássia Maciazeki-Gomes' (iD 0000-0003-4092-5262 \\ Maria Juracy Filgueiras Toneli (iD 0000-0002-931 1-5020 \\ Maria da Conceição de Oliveira Carvalho Nogueira ${ }^{3}$ (D) 0000-0002- \\ 9152-754X \\ Giovana llka Jacinto Salvaro4 (iD) 0000-0003-0884-1923 \\ 'Universidade Federal do Rio Grande, Rio Grande, RS, Brasil. 96203-900 - \\ ppgpsicologia@furg.br. \\ 2Universidade Federal de Santa Catarina, Florianópolis, SC, Brasil. 88040-900 - \\ psicologia@contato.ufsc.br \\ ${ }^{3}$ Universidade do Porto, Porto, Portugal. 4200-135 \\ 4Universidade do Extremo Sul Catarinense, Criciúma, SC, Brasil. 88806-000
}

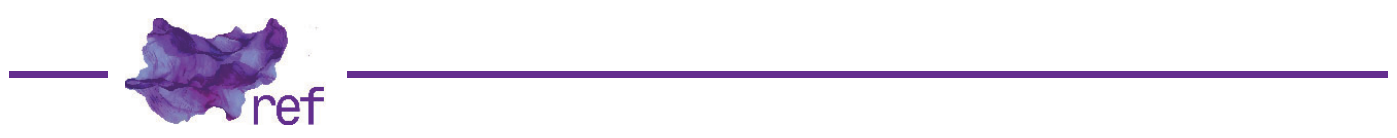

Resumo: Neste estudo, analisamos as narrativas de mulheres trabalhadoras rurais relacionadas ao trabalho no contexto da agricultura familiar. Participaram do estudo dezoito mulheres ligadas ao movimento social das trabalhadoras rurais da região noroeste do Estado do Rio Grande do Sul, Brasil. As estratégias metodológicas utilizadas obedeceram aos pressupostos da abordagem genealógica, seguindo uma perspectiva etnográfica. As narrativas produzidas expressam intersecções entre as práticas ligadas aos espaços da casa, da propriedade e do movimento social. Dos resultados produzidos emergem reflexões associadas à compreensão de trabalho como manutenção da vida e possibilidade de transformação de si e do mundo, e as relações entre trabalho e ação política são vistas como conquistas e desafios a serem enfrentados pelas mulheres trabalhadoras rurais.

Palavras-chave: trabalho; mulheres trabalhadoras rurais; ação política; movimento social; subjetividade.

Ways of Working and Ways of Subjectification in Family Agriculture in Southern Brazil

Abstract: This study analyzes the narratives of rural women workers about work in the context of family farming. Eighteen women associated with the rural workers social movement from the north-western region of the state of Rio Grande do Sul, Brazil participated in this study. The methodological strategies adopted the genealogical approach in an ethnographic perspective. The resulting narratives express intersections between practices, linking the domestic spaces, of the farm and the social movement. The research findings raise reflections associated with the understanding of work as the maintenance of life and the possibility of transforming oneself and the world while the relationships between work and political action are seen as both achievements and challenges by these female rural workers.

Keywords: Work; Female rural workers; Political action; Social movement; Subjectivity

"Se eu pudesse continuar assim, isso eu sempre peço a Deus que ele me dê saúde e essa força de eu poder trabalhar, me determinar na vida" (N.B., 59 anos).

O contexto brasileiro, nos últimos cinquenta anos, esteve marcado por uma série de mudanças, dentre elas o fim do período ditatorial e a abertura política, a proliferação de movimentos sociais de reivindicação de direitos (Maria da Glória GOHN, 2007), somado à migração de um grande contingente de pessoas do campo para a cidade. A produção agrícola passou 
por uma série de transformações tecnológicas (José VIEIRA FILHO; José SILVEIRA, 2012), políticas e econômicas, direcionadas a uma racionalidade empresarial (Carlos Rodrigues BRANDÃO, 2007). O agronegócio se consolidou como o modo de produção hegemônico e produziu efeitos nos modos de habitar, se relacionar e trabalhar.

O panorama do Censo Agropecuário de 2017 (IBGE, 2019a; 2019b) mostra que 76,8\% dos estabelecimentos brasileiros pertencem à agricultura familiar e representam $23 \%$ da área ocupada nesse âmbito. Por sua vez, os estabelecimentos não familiares compõem $23,2 \%$ do total dos estabelecimentos e representam 77\% da área ocupada. A "distribuição" da terra é desproporcional, como também são as questões econômicas daí derivadas, uma vez que, enquanto a agricultura não familiar emprega $33 \%$ da mão de obra ocupada, a agricultura familiar é responsável por $67 \%$.

O Brasil segue a manutenção histórica de desigualdades sociais, assegurada por uma estrutura agrária e fundiária de concentração de terras nas mãos de poucas pessoas que detêm grandes extensões de terras. Essa lógica se agiganta, permeada por argumentos científicotecnológicos de um "saber-poder" que respalda a normatividade das regras a serem seguidas pela racionalidade capitalista. Entre elas, um modo de produção ligado ao agronegócio para alimentar milhões de pessoas e a correlação estrita entre segurança alimentar e o compulsório consumo de alimentos com defensivos agrícolas, sendo que essas premissas já não são mais consenso na literatura (Sérgio SCHNEIDER, 2003; 2010; 2016).

Esse conjunto de transformações imprimiu novos modos de viver relacionados às questões sociais e familiares, de trabalho e renda, com o advento das "novas ruralidades" (Maria José CARNEIRO, 2008; 2012; Karen KARAM, 2004; Maria Nazareth Baudel WANDERLEY, 2012). Tendo presente este contexto agrícola, em constante transformação e propulsor de inúmeras tensões, como os embates na luta pela terra nas diferentes regiões do país, neste estudo, evocamos - pensar a partir de outras racionalidades, para além da lógica "racionalidade empresarial" capitalista que se expande no campo. Tomando como ponto de partida as ideias esboçadas por Brandão (2007) e Milton Santos (2009), propomos pensar os modos de trabalhar no campo a partir do que poderíamos chamar de contrarracionalidades expressas nos modos de produção atrelados à agricultura familiar.

Como forma de organização da vida e do trabalho, a agricultura em uma perspectiva familiar pode se opor à lógica da produção capitalista não familiar. Ao contar, de modo prioritário, com a mão de obra de cada um dos membros da família, as relações de produção apresentam especificidades na organização e nos ritmos do processo de trabalho. Wanderley (2009, p. 156) evidencia que a agricultura familiar não é uma categoria social recente, mas, no Brasil, assumiu ares de "novidade" e "renovação", o que se revela na própria definição, uma vez que, como uma categoria genérica, assume uma grande variedade de formas sociais e é "[...] entendida como aquela em que a família, ao mesmo tempo em que é proprietária dos meios de produção, assume o trabalho no estabelecimento produtivo".

Os estudos de Schneider $(2016 ; 2010)$ apresentam ênfase na agricultura familiar, na valorização das características étnicas e culturais da população local, sendo decisivos os arranjos familiares. Entre os efeitos das práticas da agricultura familiar na vida das famílias e da comunidade, estão: a) a preservação da cultura imaterial regional, como a língua, as crenças, as tradições, a gastronomia; b) a promoção da segurança alimentar da população, baseada na produção para o autoconsumo e no abastecimento de vínculos com os comércios locais; c) a melhoria das condições de vida e trabalho, e seus reflexos na saúde, educação e preservação do meio ambiente; d) a redução do uso de insumos agroquímicos e a composição de estratégias de produção mais sustentáveis, tecendo relações mais próximas e e) a corresponsabilidade entre produtor e consumidor, a diminuição da pobreza e da fome com o emprego de mão de obra na diversificação das atividades produtivas e pluriatividade (SCHNEIDER, 2010).

As mudanças que ocorreram nos modos de produção e nos arranjos familiares no que diz respeito à agricultura familiar foram acompanhadas, também, de transformações nas posições ocupadas pelas mulheres nas relações de trabalho. No Brasil, cabe lembrar que as condições de possibilidade do reconhecimento das mulheres rurais como trabalhadoras são muito recentes e remontam à década de 1980, quando a Constituição Federal de 1988 registrou o direito à remuneração do trabalho realizado pelas mulheres em contextos rurais (Rosineide de Lourdes Meira CORDEIRO, 2006). Esta conquista, recente, demarca a invisibilidade do trabalho realizado pelas mulheres rurais, mesmo exercendo longas jornadas de atividades diárias, dentro e fora de casa. O reconhecimento, na legislação brasileira, da mulher como trabalhadora rural foi, em grande medida, resultado de um longo processo de lutas e intensas mobilizações para a conquista e posterior implementação dos direitos adquiridos. Esse processo produziu efeitos nos modos de trabalhar e de subjetivar, alterando a condição das mulheres na agricultura familiar, até então tomadas como "do lar" para "trabalhadoras rurais".

Ao retomar determinadas lutas do movimento de mulheres rurais e suas conquistas, neste estudo, visamos acompanhar os efeitos dessas experiências nas narrativas de vida de mulheres 
em contextos rurais. De modo especial, centra-se no que se refere às intersecções entre gênero, trabalho e ação política, no intuito de compreender quais os efeitos dessas conquistas nas relações familiares e de trabalho, no cotidiano laboral das mulheres e, por sua vez, nos modos de se relacionar consigo e com outros.

Ancoradas nos estudos de gênero e processos de subjetivação, as reflexões aqui apresentadas são um recorte da tese de doutorado "Narrativas de si em Movimento: uma genealogia da ação política de mulheres trabalhadoras rurais do sul do Brasil" (Rita de Cássia MACIAZEKI-GOMES, 2017), em que se analisou os efeitos da ação política na produção de subjetividade de mulheres trabalhadoras rurais da região noroeste do Estado do Rio Grande do Sul, no Brasil. Para este estudo, apresentamos recortes das discussões relacionadas ao trabalho no contexto da agricultura familiar, sob o enfoque de gênero. Entre as questões disparadoras, estão: Quais os modos de trabalhar acionados em contextos rurais? E, de modo especial, quais as narrativas produzidas pelas mulheres trabalhadoras rurais acerca das experiências laborais na agricultura familiar?

Mais especificamente, no contexto da agricultura familiar, nos interessa refletir sobre os modos de trabalhar e de se subjetivar, sob o enfoque de gênero (Conceição NOGUEIRA, 2001), aqui compreendido como bandeira de lutas e como categoria de análise. A partir do que preconiza Joan Scott (1998), de uma forma mais ampla, o debate remete à compreensão do gênero em seus aspectos relacionais e de poder.

As análises propostas partem da composição do território da agricultura familiar, os modos de trabalhar e subjetivar sob as influências da colonização alemã, na região sul do Brasil, numa perspectiva de gênero. Trata-se, então, de trazer os efeitos das experiências das mulheres trabalhadoras rurais como uma produção coletiva (SCOT, 1998), incorporada às políticas particulares (SCOT, 2005) e uma produção discursiva, histórica e socialmente situada das análises (Donna HARAWAY, 1995). Assim, esse exercício reflexivo e analítico nos leva a acompanhar a produção de subjetividade (Félix GUATTARI; Suely ROLNIK, 1999) na agricultura familiar, a partir das narrativas das mulheres imersas numa cultura camponesa, de valorização da família e do trabalho, da terra como fonte de sustento e manutenção da vida por meio do trabalho familiar (Maria Ignez Silveira PAULILO, 2004). O trabalho realizado na agricultura familiar articula relações familiares, parentais, consanguíneas e também laborais. O exercício proposto está em evitar a polarização e, consequentemente, a simplificação das análises. Ao contrário, tenta buscar relacionar a multiplicidade de matizes expressas na singularidade das narrativas das mulheres trabalhadoras rurais.

Os estudos de Ellen Fensterseifer Woortmann (2000) sobre a colonização alemã no Rio Grande do Sul indicam que a família era pré-condição para posse da terra, sendo a emigração vista como um projeto familiar e não unicamente individual. A preferência na distribuição dos lotes de terras era dada aos homens casados, em detrimento aos homens solteiros. Nas linhas discursivas associadas à colonização de origem alemã, podemos identificar a presença de racionalidades atreladas a terra, ao trabalho, à família e à crença religiosa como estratégias para vencer as dificuldades encontradas no processo de imigração e organização da nova vida do outro lado do oceano.

Neste contexto, imerso nas dificuldades e nos desafios ligados à própria sobrevivência, a união da família, encadeada pelo trabalho na agricultura, se tornava fundamental. Para garantir a subsistência, a família precisaria se manter unida e organizar meios para produzir seu sustento a partir da agricultura familiar. A agricultura familiar produz modos de subjetivação singulares, atrelados à moradia, à vida em família, ao trabalho familiar compartilhado, atravessado pela cultura da colonização alemã do sul do Brasil.

A obra A ética protestante e o espírito do capitalismo, de Max Weber (2002), nos auxilia a compreender o encadeamento de saberes e práticas relacionadas aos modos de vida de descendentes da cultura alemã no Estado do Rio Grande do Sul, Brasil. A presença de um comportamento ascético denota ao trabalho um valor moral, que contribuirá para um modo de existência associada a um éthos agricultora (MACIAZEKI-GOMES et al., 2019), que produz modos de se posicionar e se relacionar diante da família e, também, do trabalho.

A produção da vida associada a um éthos agricultora diz de um modo de subjetivação permeado por saberes e poderes imersos numa conformação de forças expressas nas práticas sindicais, religiosas, feministas, ascéticas e camponesas. Diz de um modo de se relacionar consigo e com os outros, de apropriação do território da agricultura familiar do sul do Brasil que enuncia os efeitos de uma moral ascética nos hábitos, costumes e valores marcados pela colonização alemã. Nessa conformação cultural, a herança se liga à cultura e à tradição de valorização da família, trabalho e economia (oiko-nomos), ou seja, se liga à gestão da vida em família a partir da incorporação de uma moral.

A moral ascética, trazida pela colonização alemã, denota modos de empreender, construir, modificar e transformar a própria condição por meio do trabalho. É nesse sentido que o trabalhar a terra e a produção "de modo familiar" engrandece a honra, a honestidade e o nome da família. 
Concomitante à função que o ascetismo protestante teve na conformação do "espírito capitalista" weberiano, aqui, essa moralidade ganha contornos próprios na medida em que se vincula tanto à cultura camponesa (José Maria TARDIN, 2012), com sua produção para a subsistência, quanto às relações comunitárias estimuladas pelo cristianismo católico. Nessa leitura, não significa o predomínio da religião protestante, uma vez que existia uma forte presença católica na região. Em destaque, aqui, está a permanência de uma determinada cultura, na qual o trabalho se sobressai como dimensão central da existência, de modo que "a coisa mais importante era que, acima de tudo, o trabalho veio a ser considerado em si a própria finalidade da vida" e, ainda, a "falta da vontade de trabalhar é sintoma da falta de graça" (WEBER, 2002, p. 120).

Neste contexto comunitário, os laços de reciprocidade são fomentados na autoorganização social, nos empreendimentos associativos, cooperativas e, posteriormente, no movimento sindical e no movimento social de mulheres trabalhadoras rurais. O legado cultural da etnia alemã, interseccionado a outras culturas, contribui para as práticas de ação política e de autonomia comunitária. A região noroeste do Rio Grande do Sul destaca-se pela formação de uma rede econômica cooperativada, composta de estruturas de produção, de comercialização de produtos (supermercados), de cooperativa de crédito (banco comunitário) e de fornecimento de luz elétrica. A família é parte integrante da comunidade e a ela também subordinada quanto a regras, valores e costumes.

Ao levar em conta o caráter histórico, processual, relacional e situado das questões levantadas, neste estudo, temos por objetivo analisar as narrativas de mulheres trabalhadoras rurais sobre os efeitos das experiências dos modos de trabalhar e se subjetivar na agricultura familiar, na região sul do Brasil.

\section{Estratégias metodológicas}

A composição da pesquisa tomou como inspiração a abordagem genealógica de Michel Foucault (1995). A produção do percurso metodológico levou em conta a escuta, o registro e a análise das narrativas das experiências relacionadas ao trabalho para compor: a historicização de como são produzidas as práticas discursivas presentes nas relações familiares, de trabalho, espaços de ação e participação política no movimento social, nas relações consigo e com os outros; o mapeamento dos jogos de saber e poder e efeitos de subjetividade produzidos a partir das práticas, dos dispositivos.

A inserção e o acompanhamento das atividades nos espaços da casa, da propriedade e do movimento social das mulheres trabalhadoras rurais. além da realização de entrevistas semiestruturadas, compuseram o delineamento da pesquisa. Participaram 18 mulheres integrantes do Movimento Mulheres Trabalhadoras Rurais (MMTR), associadas ao Sindicato de Trabalhadores/ as Rurais.

As análises contemplaram o mapeamento dos modos de trabalhar associados às especificidades da agricultura familiar da região sul do Brasil, articulados com a inserção no movimento social de mulheres. A trajetória de vida, ligada à herança de terra, trabalho e família (MACIAZEKI-GOMES et al., 2019), narrada pelas mulheres constituiu o fio condutor das reflexões e análises.

A produção dos resultados contempla as relações e produções de gênero junto à família e ao trabalho (PAULILO, 1987; 2000; 2004; 2009), às questões econômicas e geracionais (PAULILO; Cristiani Bereta da SILVA, 2007), aos processos de escolarização; aos modos de trabalhar associados à agricultura familiar, à sucessão rural. Considerando também a apropriação de territórios que, em contextos rurais, acionam modos de vida impressos às ruralidades (WANDERLEY, 2000; MACIAZEKIGOMES; NOGUEIRA; TONELI, 2016), demarcados por uma circunscrição geográfica e também subjetiva.

\section{Modos de trabalhar e modos de subjetivar na agricultura familiar no sul do Brasil}

O estudo foi realizado em uma cidade de pequeno porte, situada na região noroeste do Estado do Rio Grande do Sul, Brasil. As participantes possuíam idades entre 30 e 67 anos. Duas eram solteiras, com 31 e 42 anos de idade e sem filhos/as. Uma das participantes, com 59 anos, era viúva, e as demais eram casadas com um/uma, dois/duas, ou três filhos/as, à exceção da participante V.B., com 30 anos, que não tinha filhos, e a participante L.P., com 67 anos e nove filhos. Em sua maioria, as mulheres possuem em média dois/duas filhos/as e referem ter vindo de uma família com uma média de oito irmãos/ãs.

Em relação à escolaridade, uma não estudou, dez cursaram o ensino fundamental incompleto, uma o ensino médio incompleto e seis o ensino médio completo. Por sua vez, a maioria relatou a baixa escolaridade ou a não escolarização dos pais. Quanto a seus filhos/as, a escolarização e a formação profissional, em nível de Ensino Médio/Técnico e Ensino Superior, 
aparecem como metas a serem atingidas, com apoio de toda família. Em sua maioria, as mulheres possuem filhos adolescentes e/ou jovens que já não residem na mesma casa. Todas se declararam agricultoras e, ao longo do texto, foram identificadas pelas iniciais do nome.

Na região noroeste do Rio Grande do Sul, devido à instabilidade climática - muita chuva ou seca - e imprevisibilidade relacionada aos rendimentos com a produção na agricultura, muitas das famílias resolveram investir na criação de gado leiteiro e fornecer leite para as indústrias lácteas da região. O ritmo deste tipo de trabalho exige dedicação das mulheres, de muitas horas por dia, mas é visto como "menos judiado" e com possibilidades de maior lucratividade do que a agricultura, que envolve um planejamento dos lucros relacionados ao ciclo de plantio até a colheita. Ainda, as mulheres estão inseridas em atividades agropecuárias ligadas à agricultura familiar, como o plantio de produtos alimentícios da horta, para consumo da família e a comercialização da produção da atividade leiteira e de produtos alimentícios como queijos, bolachas, compotas e rapaduras. Cabe às mulheres a administração de atividades domésticas, ligadas à alimentação e à higiene da casa, ao cuidado com os filhos, pessoas enfermas e/ou idosas, além do trato dos animais da propriedade. Na maioria das famílias, o trabalho é realizado pelo casal.

Para a sistematização e apresentação dos resultados, as discussões foram agrupadas em duas dimensões temáticas: (i) Do trabalho como manutenção da vida e possibilidade de transformação de si e do mundo; (ii) Das relações entre trabalho e ação política: conquistas e desafios das mulheres como trabalhadoras rurais.

\section{Do trabalho como manutenção da vida e transformação de si e do mundo}

Esta dimensão temática evoca discussões associadas à compreensão do trabalho entendido como um paradoxo (SCOT, 2005) na vida das mulheres. Ao mesmo tempo em que o trabalho pode ser tomado como uma atividade exaustiva, relacionado à subsistência e produtora de sobrecarga, também pode evocar movimentos de mudanças em relação às expectativas traçadas pelas próprias mulheres no que se refere à vida e ao futuro.

A partir dos resultados produzidos, as narrativas das trabalhadoras rurais apresentam modos de vida e de trabalho na agricultura familiar ancorados a um planejamento e organização em conjunto com a família, em detrimento a um projeto de vida individual. Desde a infância até a vida adulta, as mulheres narram trajetórias de vida marcadas pela presença de atividades laborais, bem como pelas transformações vivenciadas nos modos de trabalhar ligados à agricultura familiar. Já na infância ocorre a inserção em atividades ligadas ao plantio de alimentos e à responsabilização no cuidado de pequenos animais, como refere uma das participantes: eu sei que com seis anos eu tratava de dezoito porcos [... ] a gente trabalhava muito quando a gente era pequena (S.E., 44 anos).

As lembranças da infância reportam às dificuldades financeiras dos pais em prover a alimentação, o vestuário e o estudo para uma prole numerosa. Devido aos poucos recursos, eram priorizadas a alimentação e o vestuário. Por sua vez, o avanço na escolarização mostrava-se distante das necessidades imediatas da família. Os recursos escassos para o custeio do transporte escolar para o deslocamento, vestuário, material escolar, acrescido à perda da força de trabalho na agricultura, tornavam a frequência à escola um desafio: Nós começamos do nada e eu ainda pequena tive que morar com meus avós durante um período até para poder ir até a escola [...] depois acabei trabalhando de babá... ia para roça trabalhando cedo da manhã nos meus sete, oito anos (A.S., 42 anos). Para muitas mulheres, sua inserção nas atividades laborais, como a de outros membros da família, era importante para garantir a segurança alimentar da unidade familiar, como expressa J.B. (53 anos): tu tinhas que trabalhar na terra, pronto [...] este era o nosso sustento.

As aprendizagens, neste período, estavam associadas às atividades realizadas no cotidiano de trabalho e repassadas de geração a geração. No entanto, o desejo de estudar, ou de "ter estudado mais tempo", mostrou-se uma constante nas falas: Eu estudei até a quinta [...] mas de tanto que eu gostava de estudar, eu repeti mais meio ano a quinta série, de novo [...] eu sempre gostei de estudar (L.M., 56 anos); ou, ainda, como eu chorei, eu gostaria de ter continuado, mas os pais não tinham condições (C.W., 57 anos). Já no que se refere à família constituída, todas as mulheres afirmam que seus filhos vêm atingindo uma maior escolarização do que a sua e que o estudo é visto como uma prioridade pela família.

As transformações no mundo do trabalho produziram outros modos de pensar e se posicionar em relação à escolarização: Hoje o estudo é o primeiro, antigamente não era $\left(\mathrm{O} . \mathrm{H}_{\text {., }}\right.$ 47 anos). Um investimento maior na escolarização está diretamente relacionado à premissa de que o estudo trará uma "vida melhor" que, por sua vez, nem sempre se refere à permanência e à continuidade do trabalho no campo. Aqui, se vislumbra a problemática da migração dos mais jovens para a cidade e a questão da sucessão rural. Ao mesmo tempo em que manifestam o 
desejo de viverem próximas dos filhos, as mulheres afirmam que a vida e o trabalho no campo são "muito sofridos" e desejam aos filhos uma "vida melhor".

A partir de uma análise geracional, se observa uma melhoria da escolarização, da renda e de incremento tecnológico em relação à família de origem, como pode ser acompanhado no caso de L.P. e A.P.: Eu tirava leite de sete, oito vacas na mão (L.P., 67 anos). Na época, ela [mãe] se judiava muito. Hoje o maquinário existe para trabalhar, então ficar para se judiar não dá, porque precisa pensar na saúde (A.P., 31 anos). As mulheres referem investimentos em tecnologia, no uso de maquinários agrícolas, na reforma, ampliação ou construção da casa de moradia, aquisição de terras, ampliação do número de vacas leiteiras, melhorias na infraestrutura da unidade produtiva, como na ampliação do galpão, benfeitorias na sala de ordenha, como aquisição de ordenhadeira, resfriador de leite, entre outras.

Em grande parte, essas benfeitorias foram impulsionadas com o acesso às políticas públicas direcionadas à agricultura familiar. Destaca-se o Programa de Fortalecimento da Agricultura Familiar (PRONAF), PRONAF Mulher, Programa de Aquisição de Alimentos (PAA), Programa Nacional de Alimentação Escolar (PNAE), Programa Nacional de Apoio ao Transporte do Escolar (PNATE), Programa Nacional de Crédito Fundiário (PNCF). Além disso, conforme relatam Catia Grisa e Sergio Schneider (2015, p. 127), é central ressaltar que "em 2006, foi regulamentada a Lei da Agricultura Familiar que reconheceu a categoria social, definiu sua estrutura conceitual e passou a balizar as políticas públicas para este grupo social". Para ter acesso a essas políticas públicas, as famílias precisaram se adaptar e cumprir com as condicionalidades impostas, como a apresentação de documentação pessoal e familiar, bem como as definições claras sobre a constituição familiar e o "estado civil", para serem incluídas como beneficiárias.

Dá muita confusão essa história de solteiro e casado por causa dos negócios às vezes (risos). Quando nós fomos comprar a terra pelo banco, Banco do Brasil, daí deu rolo lá. Ficou um ano atrasado nosso financiamento. Daí o homem nos chamou lá, e disse, "afinal, o que vocês são?". Não, nós somos solteiros, mas se tiver que casar para comprar essa terra, nós vamos casar (l.M., 55 anos).

Para a contratação do crédito fundiário e ter direito a ter direitos, as políticas públicas imprimem um processo de regulamentação da vida, associado a estratégias biopolíticas enquanto uma forma de poder que governa indivíduos e o conjunto da população (FOUCAULT, 2012). A necessidade de moldagem subjetiva e familiar às políticas públicas produz outros modos de organização familiar e relacional, de acordo com premissas normativas de gênero (Judith BUTLER, 2015; Jo LITTLE; Ruth PANELLI, 2003) que trazem efeitos diretos na vida das pessoas, traduzidos na narrativa de que se tiver que casar [...] nós vamos casar (I.M., 55 anos).

Para a melhoria das condições de vida e de trabalho, as famílias se comprometeram com financiamentos de longo prazo. A ideia de virem a contrair dívidas que não possam ser honradas configura-se numa preocupação constante. A narratividade expressa pela ordem do discurso familiar orienta: tu podes ser pobre, mas nunca suja (C.W., 57 anos), ou seja, não contrair dívidas que possam vir a desonrar o nome da família. Prevalece a herança de uma moral ascética que impõe maior esforço e mais trabalho para permanecer "com o nome limpo", sem dívidas.

Se o incremento de maquinário tornou o trabalho mais leve, a sua manutenção condicionou aos membros da família o exercício de uma carga horária extensa de trabalho para honrar os compromissos financeiros com a aquisição dos produtos, sendo um ponto comum das narrativas a sobrecarga de trabalho, situação agravada com a saída dos filhos e a permanência só do casal em casa. De modo que, mesmo com o incremento de novas tecnologias, não houve diminuição no número de horas de trabalho das mulheres.

Daí, às vezes, eu me obrigo a trabalhar de noite, né. Claro, esses dias a feira era um caso especial... trabalhei assim, ... até às três da madrugada, levantei... dormi até as seis, levantei, e continuei fazendo, né, para ver se no último dia nós íamos ter produto para vender (I.M., 55 anos).

Permeada pela racionalidade patriarcal, às mulheres são atribuídas responsabilidades como as cuidadoras da família. São responsáveis pelo cuidado do marido, dos filhos, das pessoas doentes e idosas, além dos afazeres da casa, como limpeza e preparo de alimentos, e dos afazeres da propriedade - desde o trato dos animais até a produção de alimentos da horta. Ainda, junto com os filhos e com o marido realizam atividades ligadas à agricultura, para o consumo e a comercialização, e o trato com gado leiteiro, configurando práticas de cuidado imersas numa lógica normativa e patriarcal (MACIAZEKI-GOMES et al., 2019).

As tarefas relacionadas ao cuidado são historicamente atribuídas às mulheres e se integram a um conjunto de atividades que realizam como parte de um cotidiano laboral marcado pela divisão sexual do trabalho, em que 0 cuidar se produz e se legitima como responsabilidade feminina. Sobre o conceito de cuidado, Danièle Kergoat $(2016$, p. 17) demonstra que "podemos defini-lo como uma relação de serviço, apoio e assistência, remunerada ou não, que implica um sentido de responsabilidade em relação à vida e ao bem-estar de outrem". 
No sentido apresentado pela autora, as atividades de cuidado, não remuneradas, realizadas pelas mulheres agricultoras, podem ser analisadas como trabalho reprodutivo central na produção de alimentos para a subsistência e para a comercialização, uma vez que o bemestar dos integrantes da família é condição do próprio trabalho familiar nas unidades de (re) produção. Além disso, a propósito da conceituação de agricultura familiar e das narrativas analisadas neste estudo, o trabalho das mulheres é determinante no conjunto de atividades (re) produtivas realizadas nas unidades familiares.

Outros aspectos podem agravar a sobrecarga laboral das mulheres, se considerarmos a ausência de políticas públicas que possibilitem a oferta de serviços de cuidado, tais como escolas de educação infantil. Logo, para além de uma divisão sexual do trabalho mais igualitária entre mulheres e homens na família, é importante considerar o papel central do Estado na criação de políticas públicas que venham ao encontro das necessidades das populações rurais e da agricultura familiar.

As questões em destaque sobre as atividades reprodutivas e de cuidado são pertinentes, tendo em vista que o ritmo de trabalho expresso na quantidade de horas trabalhadas pelas mulheres no campo ainda é muito intenso - na quantidade e diversidade das atividades - e extenso - na quantidade de horas despendidas para a sua realização (Natália FONTOURA; Clara ARAÚJO, 2016). Durante o dia, trabalham muitas horas, porque o tempo que não estou trabalhando fora, estou trabalhando dentro [casa] (N.B., 59 anos).

Para algumas mulheres, há uma clara divisão entre as atividades exercidas dentro e fora de casa. As atividades domésticas ligadas a limpeza, manutenção e organização da casa, cuidado dos filhos e, principalmente, com os idosos acamados e doentes foram expressas como causadores de sobrecarga física e emocional.

Entre as dificuldades apontadas, aparece a necessidade de mediar os conflitos intergeracionais entre filhos/as e sogro/as que vivem na mesma casa, além da conotação de "não trabalho" dessas atividades. Entre as estratégias encontradas para solucionar os conflitos está a saída de "dentro de casa" e o ingresso nas atividades agrícolas, como expressa L.D. (43 anos): Se eu vou junto à lavoura, isso tira o stress. A ida para a lavoura está associada à ideia de "pegar no pesado", paradoxalmente produtora da sensação de alívio e de bem-estar. Sinaliza a tentativa de distanciamento das atribuições tradicionais de gênero delegadas às mulheres, causadoras de sensação de aprisionamento a partir de um modo de subjetivação expresso como "do(r) lar". Ou, ainda, nas palavras de Paulilo (1987), do "peso do trabalho leve".

A "saída de casa", vista como uma estratégia eficaz, a curto prazo, não produz, por sua vez, rupturas às demarcações tradicionais de gênero, impressas no panorama da agricultura familiar, impostas pela dupla jornada de trabalho "dentro e fora" de casa (PAULILO, 2004). A transformação da cultura familiar, no que se refere às atividades laborais nos espaços familiares, mostra-se uma das mais desafiadoras no que diz respeito às questões de gênero e trabalho.

A longa jornada de trabalho, naturalizada no cotidiano, não aparece como uma queixa na narrativa das mulheres. O exercício de atividades laborais, desde a infância, contribui para o encadeamento de experiências comuns associadas à centralidade do trabalho: Para mim, tudo é trabalho [...] não tem serviço que eu não faço (L.D., 43 anos); ou, ainda: Eu vejo o trabalho como a coisa mais importante na vida da gente. Porque tu precisa trabalhar, né? Para te sustentar [...] para sobreviver [...] (S.E., 44 anos).

O trabalho associado à sobrevivência aparece em caráter compulsório, como algo que precisa ser feito. Nesse contexto, às mulheres é expectado que desempenhem um papel de "boa mãe" e de "boa esposa", que possa apoiar e "seguir" o marido, com o objetivo de manter a família unida e produzindo junto, alimentada por uma moral religiosa de resignação e aceitação, em que cada um "dá de si", em prol da família. Na herança cultural recebida, ao homem cabe a propriedade da terra, via sucessão rural, a gerência da unidade produtiva e familiar. Esse modo familiar de organização da vida, perpassado pelas racionalidades patriarcal e religiosa, tem na aliança afetiva e financeira depositada no contrato de casamento, a manutenção do tripé terratrabalho-família (MACIAZEKI-GOMES et al., 2019).

Se o trabalho, neste sentido, produz exaustão e sofrimento, por outro lado, ele também vem acionar deslocamentos da "manutenção" para a "produção da vida". O trabalho como produção empreende esforços de transformação da condição do que se é, possibilita "se determinar na vida" e, assim, o governo de si por meio das práticas realizadas. O trabalho, como ação de si sobre si e transformação da natureza, ocupa um lugar de destaque na vida das mulheres e das famílias. Está relacionado, no caso das mulheres, a um maior grau de autonomia, como expresso: Se eu pudesse continuar assim, isso eu sempre peço a Deus que ele me dê saúde e essa força de eu poder trabalhar, me determinar na vida [...] (N.B., 59 anos).

As narrativas das mulheres apresentaram a valorização do trabalho e as fortes relações com um passado que se atualiza e se faz presente na manutenção da vida e, também, de um presente que deixa de ser, na produção de um devir outro. É visto, até mesmo, como uma estratégia de produção de saúde, nas palavras de C.W. (57 anos): Eu nem penso em parar [...] 
porque eu acho que um pouco da minha saúde é trabalhar. O trabalho dá sentido à vida, como ação posicionada, produção que instaura o reconhecimento de si. Visto como algo "que dá prazer", é lembrado como estratégia de superação e realização.

\section{Das relaçōes entre trabalho e ação política: conquistas e desafios das mulheres como trabalhadoras rurais}

A participação no movimento social de trabalhadoras rurais contribuiu para impulsionar mudanças nos modos de trabalhar na agricultura familiar. Estas mudanças estiveram associadas, em geral, aos modos de as mulheres se posicionarem nas relações familiares e de se relacionarem consigo e com os outros (MACIAZEKI-GOMES, 2017).

O processo de mobilização em prol da luta por direitos exigiu que as mulheres rurais saíssem de casa e ocupassem o espaço público, para que fossem reconhecidas como trabalhadoras rurais na Constituição Federal de 1988. O acesso aos direitos sociais e previdenciários, como o direito à aposentadoria, propiciou a valorização e reconhecimento do trabalho realizado pelas mulheres, contribuindo para que elas pudessem ocupar outros espaços, para além da esfera privada.

A implementação dessas mudanças ainda se constitui em um desafio cotidiano enfrentado pelas mulheres rurais, dentro e fora de casa. Na época, o fazer parte do movimento social significava romper com os lugares demarcados do que se esperava de uma mulher, e, por vezes, ter sua postura e comportamentos questionados pela comunidade. Para os padrões normativos, não era moralmente respeitada a mulher que não ficava em casa e "saía a andar na rua" sem o marido, ou seja, quem ousava romper com as normativas de gênero (BUTLER, 2015), de modo que, pelas suas posturas, passava a não ser "bem vista" na comunidade.

O ato de sair de casa e deixar os filhos sob a responsabilidade do marido significava, entre outras coisas, romper com a herança cultural até então designada às mulheres rurais. A conquista de direitos associados a uma profissão deixaria para trás imagens das mulheres restritas a esposa, mãe e do lar, produzidas no imaginário social. Neste sentido, é possível tecer algumas aproximações com o trabalho de Cordeiro (2006), quando se refere às dificuldades enfrentadas pelas mulheres rurais do Nordeste para conquistar uma maior liberdade de ir e vir. O "controle" e a "satisfação" dos seus atos precisavam ser "prestados" a toda comunidade que os validaria, ou não. Dentro desta conjuntura, como produzir outras possibilidades para além desta já predefinida? Como se abrir a novos processos de subjetivação e a que custo? A conquista de um maior grau de autonomia e liberdade parece estar, ainda, entre os obstáculos a serem ultrapassados na constituição de relações de gênero mais igualitárias. Incorporar outras práticas nem sempre se traduziu numa tarefa fácil para as mulheres, mas faz parte de um processo em construção em que se a gente quer mudar alguma coisa, tem que ajudar junto (V.B., 30 anos).

Ao serem questionadas sobre a profissão exercida, todas as mulheres disseram, sem hesitar: "sou agricultora". Ao se autointitularem como "agricultora", as mulheres demarcam um posicionamento político, orgulhosas pela conquista de serem consideradas "trabalhadoras rurais". Na narrativa produzida, o processo de luta das mulheres para obter o reconhecimento social e legal, na condição de trabalhadora rural, esteve marcado por uma série de desafios. Entre eles, o embate pelo direito de fazer parte dos sindicatos de trabalhadores rurais, como sócia e não mais como dependente, assim como o direito à posse compartilhada da terra com o marido (Carmen Diana DEERE, 2004).

As reivindicações dos direitos sociais e previdenciários, em especial para a aposentadoria, mobilizaram discussões dentro e fora dos espaços sindicais e produziram visibilidade ao trabalho realizado pelas mulheres (MACIAZEKI-GOMES et al., 2016). Dentro do espaço sindical, essa pauta foi propulsora de momentos tensos. As mulheres não tinham direito a ter voz ativa, nem de ser associadas ao sindicato. O marido como representante da família, o único associado, decidia - que era melhor para a família. A aprovação das mulheres na condição de associadas do Sindicato dos Trabalhadores Rurais significou o reconhecimento como trabalhadoras rurais, não mais como dependentes do marido. Ainda, a titulação como sócia do sindicato incentivou a mobilização e reivindicação de outras pautas, como o direito a ter sua própria documentação de identificação.

A afirmação e o reconhecimento como agricultora exigiam a organização da documentação formal de identificação. Ter seus próprios documentos também significava um maior grau de independência do marido, pois a primeira identidade [da mulher] era ainda o CPF do marido (G.H., 55 anos).

[...] era só o homem, o homem fazia a dívida e a mulher nem sabia o que o homem estava fazendo... nós aqui trabalhamos muito forte para que a mulher apareça e que possa assinar junto. Muitos reclamaram, muita burocracia, é difícil, mas o fato dela vir para cidade e assinar junto já é um fato que ela tá sabendo aquilo que tá sendo feito na propriedade (G.H., 55 anos) 
De posse da documentação, as mulheres puderam reivindicar a inclusão de seu nome na documentação da propriedade, bem como o acesso às políticas públicas. Por sua vez, a condição de maior participação das mulheres produziu efeitos nas relações familiares.

Para o registro das mulheres, foram organizadas as "campanhas de documentação" e a pactuação de uma identidade coletiva, incentivada pelo movimento sindical, como "agricultora". Essa movimentação produziu visibilidade às próprias mulheres sobre si mesmas, na família, na comunidade e no movimento social (Vanderléia DARON, 2003; CORDEIRO, 2004; PAULILO; SILVA, 2007; Marco Aurélio Máximo PRADO; Carmella de Paula Ferreira CAMPICl; Sara Deolinda PIMENTA, 2004; Celecina de Maria Veras SALES, 2007; Giovana Ilka Jacinto SALVARO, 2010; SALVARO; Mara Coelho de Souza LAGO; Cristina Scheibe WOLFF, 2013; 2014; Alie Van Der SCHAAF, 2003).

O reconhecimento como agricultora contribuiu para a entrada formal das mulheres nas discussões sobre a organização e o gerenciamento da unidade produtiva. A expressão "não tem chefe", utilizada por muitas ao serem indagadas sobre quem coordena a propriedade, resulta de um longo processo de luta do movimento de mulheres para a saída das mulheres da tutela do marido, para que possam se posicionar e serem ouvidas nas decisões familiares que envolvem o planejamento e execução das atividades laborais no cotidiano.

No que se refere à organização do processo de trabalho na propriedade, a maioria das mulheres afirma que as decisões e combinações são realizadas entre o casal, não tem chefe, isso a gente faz, a gente conversa (C.K., 45 anos). As questões financeiras, como a aquisição de maquinário e contratação de empréstimo para a compra de terra, até a divisão de tarefas a serem executadas na propriedade são acordadas.

[...] é só se comunicar e planejar [...] cada um sabe o que tem para fazer, quando tu estás há tantos anos no interior, tu sabes o que tem para fazer a cada semana... daí nós combinamos [...] a parte dele ele faz e quando ele precisa, ele me fala, aí a gente se prepara para eu ajudar [... ] o dia que eu preciso dele ele também me ajuda, daí ele se prepara (N.E., 36 anos).

A oportunidade de discutir e participar de atividades organizadas pelo movimento social fortaleceu a demarcação de posicionamentos mais ativos e persistentes na superação de situações de opressão enfrentadas (MACIAZEKI-GOMES; Judit HERRERA ORTUÑO, 2020). As mulheres afirmam que essas discussões contribuíram para repensar sua condição e se (re)posicionar dentro de casa, o que não significa a ausência de tensionamentos e embates. Nós fomos defender uma política voltada para a agricultura familiar [...] eu sei que é muito difícil, que às vezes nós somos criticadas, mas nunca desistam por isso, gurias, tenham orgulho de estar aí, de terem saído de casa (S.E., 44 anos). A saída de casa, no contexto da agricultura familiar, pode ser associada à construção de relações mais igualitárias, seja no cuidado dos filhos, seja nos afazeres na unidade produtiva, como também da reivindicação de direitos com a implementação de políticas públicas.

No entanto, a divisão e a realização das tarefas domésticas foram apontadas como desafios ainda enfrentados pelas mulheres. A participação do marido nas atividades domésticas é vista como "ajuda" e as mulheres tomam para si a responsabilidade e o "dever" de realizálas. Como já assinalado, há uma avaliação do trabalho como exaustivo, devido à grande quantidade de horas trabalhadas por dia, mas, ao mesmo tempo, a possibilidade de trabalhar é tomada como uma gratificação pessoal e social. Na cultura regional, o uso da expressão "a gente é alemoa" estabelece uma relação com a herança moral ascética da valoração positiva do trabalho, como meio imediato para reconhecimento social, sendo que ser considerada uma mulher "trabalhadora" é extremamente valorizado pela comunidade.

Na unidade produtiva, o trabalho não realizado se acumula ao do dia seguinte. A necessidade de uma extensa carga horária despendida pelas mulheres está associada à escassez da mão de obra e à dificuldade de participação, mais constante, no movimento social de mulheres trabalhadoras rurais. Se, por um lado, entre as transformações ocorridas nos últimos anos, está a melhoria no processo de trabalho com o incremento de tecnologia, a diminuição da prole resultou na redução da força de trabalho familiar, que contribuiu para a dificuldade das mulheres de se ausentarem da propriedade. A sobrecarga laboral executada pelo casal é naturalizada, vista como algo de que se precisa "dar conta", administrar e organizar o processo de trabalho: A gente nunca tem férias, sabe, eu acho que é pouca, pouca gente para fazer tudo (N.E., 36 anos).

Assim, entre os desafios enfrentados, mesmo com sinalização de melhoria das condições de trabalho, está o equilíbrio entre um modo exaustivo, "judiado", marcado pela busca da sobrevivência, e a ideia que por comida não se briga mais, pois os tempos são outros, como diz I.M. (55 anos).

Eu acho que dinheiro não deve mais ser problema hoje em dia. Por mais que a gente rala [trabalha muito] dia e noite. Eu não sei [...], nós temos muitos esses resquícios do passado, na colônia também. As pessoas morriam de fome, literalmente, no meio do mato. Não tinha dinheiro. Não tinha acesso à saúde, a nada. Mas os tempos são outros, então vamos parar de 
brigar por coisas que não existem mais... então, a vida pode ser mais light [...] tem que ser tudo diferente, né. Se a vida está melhor, ela tem que estar melhor de fato, né (I.M., 55 anos).

A incorporação dessas mudanças significa, entre outras coisas, atentar para a alteração nos modos de ver, sentir e se pensar no mundo. O trabalho no histórico das famílias se constituiu de modo central, atrelado à manutenção e, aos poucos, parece se deslocar para a produção da vida.

O trabalho como produção demarca a ideia de algo essencial e necessário na vida, o que parece sinalizar deslocamentos, como uma atividade que pode ser pensada, discutida e realizada em família. Nesse sentido, a participação no movimento social de mulheres contribuiu para propiciar movimentos de mudanças iniciados pelas mulheres. Ao trabalho passa a ser atribuída uma conotação positiva, como transformação da condição que se vive, condição de possibilidade de "se determinar na vida", num exercício do governo de si por meio das práticas realizadas. Vem instaurar, nesse processo, modos de trabalhar que acionam modos de subjetivar (Tania Mara Galli FONSECA, 2002).

\section{Consideraçōes finais}

Neste estudo, analisamos as narrativas de mulheres trabalhadoras rurais sobre os efeitos das experiências dos modos de trabalhar e se subjetivar na agricultura familiar, na região noroeste do Estado do Rio Grande do Sul do Brasil. As narrativas produzidas expressam intersecções entre as práticas ligadas aos espaços da casa, da propriedade e do movimento social. As análises estão inseridas no território da agricultura familiar, nos modos de trabalhar e subjetivar sob as influências da colonização alemã, na região sul do Brasil, numa perspectiva de gênero, discursiva, histórica e socialmente situada.

Dos resultados produzidos emergem reflexões associadas à compreensão de trabalho como manutenção da vida e possibilidade de transformação de si e do mundo. O trabalho na agricultura familiar, no sul do Brasil, apresenta especificidades, entre elas a de que as atividades laborais, realizadas no circuito familiar, se mesclam com as relações afetivo-familiares. Na família, cada pessoa precisa trabalhar e fazer a sua parte em prol da geração de renda da família. A organização das rotinas de trabalho está atrelada às condições climáticas, mas também aos costumes e às tradições familiares.

Na narrativa das mulheres, a valoração do trabalho aparece como algo constituinte. O trabalho realizado pelas mulheres se torna fundamental para a organização produtiva e econômica da família, garantindo a "manutenção da vida". No entanto, este trabalho nem sempre é reconhecido e muito menos valorizado pela família e até mesmo pela comunidade. De modo paradoxal, ao mesmo tempo em que expressam cansaço, decorrente das longas jornadas dentro e fora de casa, as mulheres também associam ao trabalho as sensações de bem-estar, satisfação, realização e força. Assim, como possibilidade de transformação de si e de sua condição de vida. Para além de suprir as necessidades financeiras e de sobrevivência imediata, de "manutenção da vida", o trabalho está relacionado à "produção da vida". Está imerso em uma historicidade, atrelado às memórias de um passado que se reatualiza, tendo no sacrifício do corpo o suporte e alívio das dores. Ao problematizar como as práticas relacionadas ao trabalho estão sendo efetivadas, as mulheres não demonstram intenção de parar de trabalhar, mas de compor outros modos de trabalhar.

As dificuldades são muitas, mesmo diante das transformações acionadas pelas novas ruralidades. Com o passar dos anos, houve melhoria das condições de trabalho, com o implemento de tecnologia e infraestrutura, diversificação do trabalho realizado e acesso às linhas de crédito de programas sociais do governo brasileiro. No entanto, não se observa uma diminuição da carga horária, intensa e extensa, do trabalho realizado. No que pese a divisão das tarefas entre o casal, a mulher permanece com uma jornada maior de atividades e continua como responsável por dar conta das tarefas "dentro e fora de casa". Por outro lado, os casais parecem constituir relações mais flexíveis e abertas às negociações sobre como organizar as atividades de trabalho.

As relações entre trabalho e ação política são vistas como conquistas e desafios a serem enfrentados pelas mulheres trabalhadoras rurais. Destaca-se que a inserção e a participação das mulheres no movimento de mulheres trabalhadoras rurais instituíram fissuras na divisão sexual do trabalho na família. A adesão e a participação no movimento de mulheres abriram espaços para a discussão de ideias, até então, naturalizadas dentro do contexto familiar.

Com a saída de casa e um maior envolvimento nas atividades do movimento de mulheres, tratativas e (re)adequações entre o casal precisaram ser feitas. O espaço do movimento social de mulheres se mostrou propício à movimentação da vida, ao pautar questões e desafios presentes no cotidiano de trabalho das mulheres agricultoras. Ao abrir brechas e fazer pensar, potencializou memórias e conquistas coletivas, como a aquisição dos direitos sociais e previdenciários, vindo a contribuir com estratégias de resistência e criação nos modos de trabalhar aliados à "movimentação" da vida e, não, a seu aprisionamento e sofrimento. 
O trabalho como "manutenção, produção e movimentação" da vida não sinaliza etapas vencidas, ou, ainda, barreiras já ultrapassadas pelas mulheres. Sinaliza interfaces de um mesmo processo na busca de ressignificação dos modos de trabalhar, de reflexão e problematização das condições de (in)visibilidade e de reconhecimento do trabalho realizado. O trabalho como uma dimensão constitutiva de um éthos agricultora confere às mulheres identidade como trabalhadoras rurais, de modo que a luta pelo reconhecimento dessa condição opera como dispositivo de subjetivação junto à agricultura familiar.

\section{Referências}

BRANDÃO, Carlos Rodrigues. "Tempos e Espaços nos mundos rurais do Brasil". Ruris, Campinas, v. 1, n. 1, p. 37-64, 2007. Disponível em https://www.ifch.unicamp.br/ojs/index.php/ruris/article/ view/643/511. Acesso em 16/06/2019.

BUTLER, Judith. Problemas de gênero. Feminismo e subversão da identidade. Rio de Janeiro: Civilização Brasileira, 2015.

CARNEIRO, Maria José. "O rural como categoria de pensamento". Ruris, Campinas, v. 2, n. 1, p. 9-38, 2008.

CARNEIRO, Maria José (Ed.). Ruralidades contemporâneas: modos de viver e pensar o rural na sociedade brasileira. Rio de Janeiro: Mauad; FAPERJ, 2012.

CORDEIRO, Rosineide de Lourdes Meira. Além das secas e das chuvas. O uso da nomeação da mulher trabalhadora rural no sertão central de Pernambuco. 2004. Tese (Doutorado) - Programa de Pós-Graduação em Psicologia, Pontifícia Universidade Católica de São Paulo, São Paulo, Brasil.

CORDEIRO, Rosineide de Lourdes Meira. "Além das secas e das chuvas. O uso da nomeação da mulher trabalhadora rural no sertão central de Pernambuco". In: WOORTMANN, Ellen Fensterseifer; HEREDIA, Beatriz; MENASHE, Renata (Orgs.). Margarida Alves. Coletânea sobre estudos rurais e gênero. Brasília: MDA/IICA, 2006. p. 216-244

DARON, Vanderléia L. P. Educação, cultura popular e saúde: experiências de mulheres trabalhadoras rurais. 2003. Dissertação (Mestrado) - Programa de Pós-Graduação em Educação, Universidade de Passo Fundo, Passo Fundo, Brasil.

DEERE, Carmen Diana. "Os direitos da mulher a terra e os movimentos sociais rurais na reforma agrária brasileira". Revista Estudos Feministas, Florianópolis, v. 12, n. 1, p. 175-204, jan./abr. 2004.

FONSECA, Tania Mara Galli. Modos de trabalhar, modos de subjetivar. Tempos de reestruturação produtiva: um estudo de caso. Porto Alegre: EDUFRGS, 2002.

FONTOURA, Natália; ARAÚJO, Clara (Orgs.). Uso do tempo e gênero. Rio de Janeiro: EDUERJ, 2016. Disponível em http://repositorio.ipea.gov.br/bitstream/1 1058/8034/1/Uso\%20do\%20tempo\%20 e\%20g\%C3\%AAnero.pdf. Acesso em 23/03/2019.

FOUCAULT, Michel. "Nietzsche, a genealogia e a história". In: FOUCAULT, Michel. Microfísica do Poder. Rio de Janeiro: Graal, 1995. p. 15-38.

FOUCAULT, Michel. "Governamentalidade". In: FOUCAULT, Michel. Ditos \& Escritos N. Estratégia, saber e poder. Rio de Janeiro: Forense Universitária, 2012. p. 275-298.

GOHN, Maria da Glória. Teorias dos Movimentos Sociais. Paradigmas Clássicos e Contemporâneos. 6. ed. São Paulo: Loyola, 2007.

GRISA, Catia; SCHNEIDER, Sergio. "Três Gerações de Políticas Públicas para a Agricultura Familiar e Formas de Interação entre Sociedade e Estado no Brasil". RESR, Piracicaba-SP, v. 52, Supl. 1, p. S125-S146, 2014. Disponível em http://www.scielo.br/pdf/resr/v52s1/a07v52s1.pdf. Acesso em 23/03/2019.

GUATTARI, Félix; ROLNIK, Suely. Micropolítica: Cartografia do desejo. Petrópolis: Vozes, 1999.

HARAWAY, Donna. "Saberes localizados: a questão da ciência para o feminismo e o privilégio da perspectiva parcial". Cadernos Pagu, Campinas, v. 5, p. 7-41, 1995.

IBGE. "Censo Agropecuário 2017. Retratando a realidade do Brasil agrário". Agência IBGE de Notícias, 2019a. Disponível em https://agenciadenoticias.ibge.gov.br/media/com mediaibge/ arquivos/d37d30efd337a9b66852d60148695df1.pdf. Acesso em 06/04/2020. 
IBGE. "Censo Agro 2017: população ocupada nos estabelecimentos agropecuários cai 8,8\%". Agência IBGE de Notícias, 2019b. Disponível em https://agenciadenoticias.ibge.gov.br/agenciasala-de-imprensa/2013-agencia-de-noticias/releases/25789-censo-agro-2017-populacaoocupada-nos-estabelecimentos-agropecuarios-cai-8-8. Acesso em 06/04/2020.

KARAM, Karen F. "A mulher na agricultura orgânica e em novas ruralidades". Revista Estudos Feministas, Florianópolis, v. 12, n. 1, p. 303-320, jan./abr. 2004.

KERGOAT, Danièle. "O cuidado e a imbricação das relações sociais". In: ABREU, Alice Rangel de P.; HIRATA, Helena; LOMBARDI, Maria Rosa (Orgs.). Gênero e trabalho no Brasil e na França: perspectivas interseccionais. São Paulo: Boitempo, 2016. p. 17-26.

LITLE, Jo; PANELLI, Ruth. "Gender Research in Rural Geography". Gender, Place and Culture, v. 10, n. 3, p. 281-289, 2003.

MACIAZEKI-GOMES, Rita de Cássia; HERRERA ORTUÑO, Judit. "Devir Margarida: narrativas de si em experienciafetos". Interface, Botucatu, v. 24, e190180, 2020. Disponível em hittps://www.scielo.br/ pdf/icse/v24/1807-5762-icse-24-e190180.pdf.

MACIAZEKI-GOMES, Rita de Cássia; TONELI, Maria Juracy Filgueiras; NOGUEIRA, Conceição; GRAVE, Rita. "Ação política e produção de subjetividade: a herança de terra, trabalho e participação política na produção de um éthos agricultora". Estudos de Psicologia, Natal, v. 24, n. 3, p. 305-316, 2019.

MACIAZEKI-GOMES, Rita de Cássia. Narrativas de si em movimento. Uma genealogia da ação politica de mulheres trabalhadoras rurais do sul do Brasil. 2017. Tese (Doutorado) - Programa de Pós-Graduação em Psicologia, Universidade do Porto, Porto, Portugal.

MACIAZEKI-GOMES, Rita de Cássia; NOGUEIRA, Conceição; TONELI, Maria Juracy Filgueiras. "Mulheres em contextos rurais: um mapeamento sobre gênero e ruralidade". Psicologia \& Sociedade, Belo Horizonte, v. 28, n. 1, p. 115-124, jan./abr. 2016.

MACIAZEKI-GOMES, Rita de Cássia; VÁSQUEZ, Claudia Lazcano; NOGUEIRA, Conceição; TONELI, Maria Juracy Filgueiras. "Participação política e subjetividade - Narrativas de vida de trabalhadoras rurais do sul do Brasil". PSICO, Porto Alegre, v. 47, n. 2, p. 148-158, 2016.

NOGUEIRA, Conceição. Um novo olhar sobre as relações de género. Feminismo e perspectivas críticas na psicologia social. Lisboa: Calouste Gulbenkian, 2001.

PAULILO, Maria Ignez Silveira. "O peso do trabalho leve". Ciência Hoje, v. 28, p. 1-7, 1987. Disponível em http://naf.ufsc. br/files/2010/09/OPesodoTrabalhoLeve.pdf. Acesso em 23/03/2019.

PAULILO, Maria Ignez Silveira. "Movimento de mulheres agricultoras: terra e matrimônio". Cadernos de Pesquisa, Florianópolis, v. 21, p. 1-17, 2000.

PAULILO, Maria Ignez Silveira. "Trabalho familiar: uma categoria esquecida de análise". Revista Estudos Feministas, Florianópolis, v. 12, n. 1, p. 229-252, jan./abr. 2004.

PAULILO, Maria Ignez Silveira; SILVA, Cristiani Bereta da. "A luta das mulheres agricultoras: entrevista com Dona Adélia Schmitz". Revista Estudos Feministas, Florianópolis, v. 15, n. 2, p. 399-417, maio/ ago. 2007.

PAULILO, Maria Ignez Silveira. "Movimento das mulheres agricultoras e os muitos sentidos da igualdade de gênero". In: FERNANDES, Bernardo Mançano; MEDEIROS, Leonilde Servolo; PAULILO, Maria Ignez (Orgs.). Lutas camponesas contemporâneas: condições, dilemas e conquistas: a diversidade das formas das lutas no campo. 2. ed. São Paulo: EDUNESP; Brasilia: NEAD, 2009. p. $179-202$.

PRADO, Marco Aurélio Máximo; CAMPICl, Carmella de Paula Ferreira; PIMENTA, Sara Deolinda. "Identidade coletiva e política na trajetória de organização das trabalhadoras rurais de Minas Gerais: para uma psicologia política das ações coletivas". Psicologia em Revista, Belo Horizonte, v. 10, n. 16, p. 298-317, 2004

SALES, Celecina de Maria Veras. "Mulheres rurais: tecendo novas relações e reconhecendo direitos". Revista Estudos Feministas, Florianópolis, v. 15, n. 2, p. 437-443, maio/ago. 2007. 
SALVARO, Giovana llka Jacinto. Entre a igualdade e a diferença: mulheres camponesas em lutas de gênero. 2010. Tese (Doutorado) - Programa de Pós-Graduação Interdisciplinar em Ciências Humanas, Universidade Federal de Santa Catarina, Florianópolis, Brasil.

SALVARO, Giovana Ilka Jacinto; LAGO, Mara Coelho de Souza; WOLFF, Cristina Scheibe. "Mulheres agricultoras e mulheres camponesas: lutas de gênero, identidades políticas e subjetividades". Psicologia \& Sociedade, Belo Horizonte, v. 25, n. 1, p. 79-89, 2013.

SALVARO, Giovana Ilka Jacinto; LAGO, Mara Coelho de Souza; WOLFF, Cristina Scheibe. "Limites e possibilidades da militância política em um movimento social rural de mulheres". Revista Estudos Feministas, Florianópolis, v. 22, n. 1, p. 51-70, jan./abr. 2014.

SANTOS, Milton. A natureza do espaço. Técnica e tempo, razão e emoção. 4. ed. 5. reimpr. São Paulo: EDUSP, 2009.

SCHAAF, Alie Van Der. "Jeito de mulher rural: a busca de direitos sociais e da igualdade de gênero no Rio Grande do Sul". Sociologias, Porto Alegre, v. 10, n. 5, p. 412-442, 2003.

SCHNEIDER, Sérgio. "Teoria social, agricultura familiar e pluriatividade". Revista Brasileira de Ciências Sociais, São Paulo, v. 18, n. 51, p. 99-121, 2003.

SCHNEIDER, Sérgio. "Reflexões sobre diversidade e diversificação: Agricultura, formas familiares e desenvolvimento rural". Ruris, Campinas, v. 4, n. 1, p. 85-131, 2010.

SCHNEIDER, Sérgio. "A Presença e as Potencialidades da Agricultura Familiar na América Latina e no Caribe". Redes, Santa Cruz do Sul, v. 21, n. 3, p. 11-43, set./dez. 2016.

SCOT, Joan. "A invisibilidade da experiência". Projeto História, São Paulo, v. 16, p. 297-325, 1998.

SCOIT, Joan. "O enigma da igualdade". Revista Estudos Feministas, Florianópolis, v. 13, n. 1, p. 11 30, jan./abr. 2005.

TARDIN, José Maria. "Cultura Camponesa". In: CALDART, Roseli Salete et al. (Orgs.). Dicionário da Educação do campo. Rio de Janeiro; São Paulo: Escola Politécnica de Saúde Joaquim Venâncio; Expressão Popular, 2012. p. 180-192.

VIEIRA FILHO, José E. R.; SILVEIRA, José Maria F. J. "Mudança tecnológica na agricultura: uma revisão crítica da literatura e o papel das economias de aprendizado". Revista de Economia e Sociologia Rural, Brasília, v. 50, n. 4, p. 721-742, 2012.

WANDERLEY, Maria de Nazareth Baudel. "A valorização da agricultura familiar e a reivindicação da ruralidade no Brasil". Desenvolvimento e Meio Ambiente, v. 2, p. 29-37, 2000.

WANDERLEY, Maria de Nazareth Baudel. "Raízes históricas do campesinato brasileiro". In: WANDERLEY, Maria de Nazareth Baudel. Mundo rural como um espaço de vida. Porto Alegre: EDUFRGS, 2009. p. 155-183.

WANDERLEY, Maria de Nazareth Baudel. "Prefácio". In: CARNEIRO, Maria José (Ed.). Ruralidades contemporâneas: modos de viver e pensar o rural na sociedade brasileira. Rio de Janeiro: Mauad; FAPERJ, 2012. p. 23-50.

WEBER, Max. A estética protestante e o espírito do capitalismo. São Paulo: Martin Claret, 2002.

WOORTMANN, Ellen Fensterseifer. "Identidades e memórias entre teutobrasileiros: os dois lados do Atlântico". Horizontes Antropológicos, Porto Alegre, v. 6, n. 14, p. 205-238, 2000.

Rita de Cássia Maciazeki-Gomes (ritamaciazeki@furg.br) é Professora Adjunta do Instituto de Ciências e da Informação da Universidade Federal do Rio Grande (FURG), onde leciona e orienta no Programa de Pós-Graduação em Psicologia (PPGPSI), Graduação em Psicologia e Residência Multiprofissional em Saúde da Família. Cofundadora do Grupo de Estudos em Saúde Coletiva dos Ecossistemas Costeiros e Marítimos (GESCEM-FURG).

Maria Juracy Filgueiras Toneli (juracy.toneli@gmail.com) é Professora Titular do Departamento de Psicologia da UFSC, onde leciona e orienta na pós-graduação (PPGP), pesquisadora 1A do CNPq, cofundadora do Núcleo Margens: Modos de vida, família e relações de gênero (PSI/UFSC), conselheira do CFP (Conselho Federal de Psicologia - 2020-2022). 
Maria da Conceiçāo de Oliveira Carvalho Nogueira (cnogueira@fpce.up.pt) é Doutora em Psicologia Social na Universidade do Minho, Professora Associada com Agregação na Universidade do Porto, Programa Doutoral de Psicologia da Faculdade de Psicologia e Ciências da Educação (FPCE-UP). Atua na área de Ciências Sociais com ênfase em Psicologia Social e nesta no domínio dos Estudos de Género e Sexualidades.

Giovana Ilka Jacinto Salvaro (giovanailka@gmail.com) é Professora dos Programas de Pós-Graduação em Desenvolvimento Socioeconômico (PPGDS) e Direito (PPGD) dos cursos de Graduação em Psicologia e Direito da Universidade do Extremo Sul Catarinense (UNESC).

\section{COMO CITAR ESSE ARTIGO DE ACORDO COM AS NORMAS DA REVISTA}

MACIAZEKI-GOMES, Rita de Cássia; TONELI, Maria Juracy Filgueiras; NOGUEIRA, Maria da Conceição de Oliveira Carvalho; SALVARO, Giovana llka Jacinto. "Modos de trabalhar e modos de subjetivar na agricultura familiar no sul do Brasil". Revista Estudos Feministas, Florianópolis, v. 29, n. 1, e65762, 2021.

\section{CONTRIBUIÇĀO DE AUTORIA}

Rita de Cássia Maciazeki-Gomes atuou na concepção, coleta de dados e análise de dados, elaboração do manuscrito, redação, discussão de resultados.

Maria Juracy Filgueiras Toneli atuou na discussão dos resultados e revisão da redação do manuscrito.

Maria da Conceição de Oliveira Carvalho Nogueira atuou na discussão dos resultados e revisão da redação do manuscrito.

Giovana llka Jacinto Salvaro ałuou na redação e revisão do manuscrito.

\section{FINANCIAMENTO}

Agência de fomento CNPq - Bolsa de Demanda Social concedida à primeira autora, para realização de doutorado em Psicologia na Faculdade de Psicologia e Ciências da Educação da Universidade do Porto.

\section{CONSENTIMENTO DE USO DE IMAGEM}

Não se aplica.

\section{APROVAÇÃO DE COMITÊ DE ÉTICA EM PESQUISA}

Aprovado Parecer 118.600 - CEP-UNIJUÍ-RS.

\section{CONFLITO DE INTERESSES}

Não se aplica.

\section{LICENÇA DE USO}

Este artigo está licenciado sob a Licença Creative Commons CC-BY 4.0 International. Com essa licença você pode compartilhar, adaptar, criar para qualquer fim, desde que atribua a autoria da obra.

\section{HISTÓRICO}

Recebido em 17/06/2019

Reapresentado em 17/04/2020

Aprovado em 09/06/2020 